\title{
ANÁLISIS CRÍTICO DE LA IMAGEN DE LA JUVENTUD EN EL DISCURSO PUBLICITARIO
}

\section{Critical analysis of the image of youth in the advertising discourse}

\author{
Miguel Angel Nicolas Ojeda ${ }^{1}$
}

\section{Resumen}

El propósito de este trabajo es ofrecer una reflexión sobre el actual fenómeno publicitario y sobre el papel que ejerce en nuestras sociedades en la construcción y reconocimiento de los sentidos que define el concepto actual de juventud. De este modo, ponemos en práctica un modelo semiótico crítico del texto publicitario para analizar los mecanismos utilizados en los mensajes publicitarios, las características de su lenguaje y los principales significados asociados a las imágenes de la juventud utilizadas en los anuncios.

Palabras-clave: juventud, semiótica, publicidad, discurso, imagen.

\section{Resumo}

O propósito deste trabalho é oferecer uma reflexão sobre o atual fenômeno publicitário e sobre o papel que ele exerce em nossas sociedades na construção e reconhecimento dos sentidos que definem o conceito atual de juventude. Deste modo, poremos em prática um modelo semiótico crítico do texto publicitário para analisar os mecanismos utilizados nas mensagens publicitárias, as características de sua linguagem e os principais significados associados às imagens da juventude utilizadas nos anúncios.

Palavras-chave: juventude, semiótica, publicidade, discurso, imagem.

\begin{abstract}
This work is a reflection of the advertising phenomenon and the role it occupies in our society in the construction of meaning the concept of youth. To do this, we use a semiotic critical model advertising discourse to discover the mechanisms used by the advertising to create the sense of images of youth used in their texts.
\end{abstract}

Keywords: youth, semiotics, advertising, text, image.

\footnotetext{
${ }^{1}$ Doctor en Publicidad y profesor en la Universidad Católica San Antonio de Murcia (UCAM) donde imparte las asignaturas de Lenguaje Publicitario, Planificación de Médios y Creatividad Aplicada. Dirección: Campus de Los Jerónimos. 30107, Guadalupe (Murcia) Espana.
} 


\section{INTRODUCCIÓN}

Nuestro estudio de las imágenes de la juventud en el discurso publicitario recoge una aproximación a la comprensión crítica del fenómeno publicitario desde la disciplina social de la comunicación. Un planteamiento que analiza el rol de las imágenes de jóvenes en el discurso publicitario, su colaboración en la construcción social de concepto de juventud en sí y su utilización en el mecanismo de la comercialización y consumo de productos. Para este fin, creemos acertado delimitar nuestras palabras y nuestro ámbito de estudio para no transferir un significado tan generalizado de la praxis profesional publicitaria, ya que presupone que sobre esta recae toda la responsabilidad sobre la aceptación o rechazo del producto o servicio anunciado, negando de esta manera lo obvio: naturaleza del producto, beneficios, usos, funciones, necesidades del consumidor, tipología de consumidor, medios utilizados, precio, puntos de venta o distribución, marca, etc.

Nuestro trabajo pertenece al ámbito de la disciplina publicitaria científica y su objeto de estudio es doble: la juventud y el discurso publicitario; el estudio de la representación de la juventud en la publicidad y el de las características del lenguaje publicitario utilizado. Para este propósito el trabajo se divide en distintos epígrafes que tratan de dar respuesta a nuestros propósitos. En el epígrafe 2 "Metodología para el estudio de la representación de la juventud en el discurso publicitario", delimitamos nuestro modelo de análisis, así como las características de la muestra utilizada y los soportes escogidos. En el epígrafe 3 "Categorización de personajes en el discurso publicitario analizado" catalogamos seis perfiles juveniles (imágenes conceptuales) con mayor frecuencia y representatividad de nuestro análisis y, finalmente, el epígrafe 4 "Conclusiones" aporta las reflexiones y conclusiones acerca de la presencia, utilización y construcción/transformación de imágenes juveniles en el discurso o discursos publicitarios, así como de los significados asociados a estas imágenes en relación al tipo de sector o producto/marca que más potencia su utilización y desgaste en el texto.

2. PROPUESTA METODOLOGÍA PARA EL ESTUDIO DE LA REPRESENTACIÓN DE LA JUVENTUD EN EL DISCURSO PUBLICITARIO 
Por repetitivo que resulte afirmarlo, convivimos en entornos comunicativos continuamente cambiantes, en evolución continua por propia naturaleza, por propia condición. Esta evolución condiciona nuestra aportación a la discusión sobre la capacidad de la comunicación publicitaria para participar de la construcción de discursos sociales creadores de sentido cultural y antropológico, en definitiva para convertirse en uno de los principales vehículos de cohesión social a través de los discursos y sus sentidos, liberada de las grandes ideologías o creencias religiosas. Si bien, su principal propósito (o punto de partida) no es, mejor dicho, no era la cohesión social, sino funcionar como herramienta, como catalizador del consumo masivo y la demanda de productos, lo que la definía como en una herramienta pragmática al servicio de la economía, en realidad, la publicidad, como nos recuerda Antonio Caro, tras estudiar las aportaciones de Sut Jhally y Jesús Ibáñez, ni anuncia los productos ni activa la demanda, sino que "la publicidad constituye el instrumento hoy por hoy imprescindible para imaginarizar los productos y todo tipo de entidades a través de las marcas; las cuales pasan a constituir, como resultado de este verdadero proceso de transmutación cabalística, su verdadera entidad". En nuestro trabajo "Publicidad y Juventud" (2008), así como en otros trabajos que ofrecen resultados parciales respecto del que aquí presentamos, hemos ido delimitando nuestra delimitación o perspectiva científica desde la que nos acercamos al estudio del fenómeno publicitario y en particular al estudio y análisis de la publicidad como discurso social generador de sentidos colectivos en torno a la juventud a partir de una perspectiva semiótica. La publicidad actual, como hemos dicho, no puede ser comprendida solamente como un enlace entre el producto y el consumidor, "la publicidad es más que eso, es la encargada de crear <<nuevos significados>> y de unirlos a los productos. En la comunicación publicitaria, en el enlace entre productores y consumidores, intervienen muchos elementos que no son estrictamente mecanismo publicitarios, pero la creación de esos significados y su vinculación a los productos es el trabajo inexcusable del publicitario" (Eguizabal 2009:394). En este mimo sentido se manifiesta este trabajo con el propósito de recoger esos "nuevos significados" o simplemente "conjunto de significados", pero no los asociados en los productos, sino los asociados a dichos productos en relación con las imágenes juveniles, sean estas o no representaciones ideales de los consumidores 
juveniles, es decir, atendiendo y diferenciando en cada caso el rol que esa imagen juvenil desempeña en la configuración del texto publicitario.

Por estas razones, nuestra propuesta necesita, en todo caso y en primer lugar, de una comprensión sociológica, psicológica y antropológica del concepto social de juventud. Así, para la comprensión y posterior identificación de los etilos de vida juveniles, las subculturas juveniles $\mathrm{y}$, en general, de los elementos o signos que configuran uma cultura juvenil nuestros trabajos han tomado como referencia teórica los trabajos de la Sociologia y la Antropologia. Así, autores como Alberck y Rosnmaruy, Bergua Amores, Comas, Costa, Perez Tornero, Tropea, Carles Feixa, Gil Calvo, Lozano, Martín Criado, Martín Serrano, Muñoz, Juan Carlos Revilla, Romero, Ruiz de Olabuenaga, entre otros nos han permitido establecer el conocemiento teórico para delimitar los elementos de las culturas juveniles y los estilos de vida presentes en los textos publicitários analizados.

Nuestra metodología parte de la construcción de un modelo de tradición semiótica centrado en el estudio sintáctico y semántico del texto publicitario. Entre las principales variables que configuran este modelo resaltamos: Sector; Anunciante/Marca; Producto anunciado; Eslogan del anuncio y/o la marca; Concepto de comunicación utilizado ((Denotaciones y connotaciones de los signos utilizados); Principal promesa o eje psicológico del producto o marca; Utilización de figuras retóricas (relación texto e imagen); Narración literal del mensaje; Variables sociodemográficas que definen estéticamente a los personajes del anuncio: A. Sexo. B. Edad. C. Raza, D. Clase social; Estilo de vida de los personajes (juveniles); Rol de los personajes; Significados, características, conducta o juicios de valor atribuidos a los personajes; Ambiente; Estética o referencia a las subcultura juveniles, Uso cromático, etc.

Por finalizar com las delimitaciones metodológicas, debemos reocordar que este texto presenta las conclusiones extraídas del estúdio de una muestra de más de 1000 anuncios gráficos extraídos de los periódicos de información general (no temática, como los deportivos) com mayor audiencia y tirada en España durante el intervalo de tiempo 2000-2006. En este trabajo no recogemos los datos estadísticos de cada una de las variables estructuradas según sector o anunciante. Nuestro propósito es ofrecer a la comunidad científica las prinipales reflexiones extraídas del análisis de los distintos resultados para que puedan ser repensadas o tomadas en cuenta por parte de aquellos investigadores interesados en el estudio de la juventud y el estudio de la representación 
y el discurso publicitário. Así, ofrecemos en el siguiente epígrafe el conjunto de representaciones de la juventud, sus usos y los significados que las definen que, según nuestro análisis, cuentan com mayor presencia en nuestra muestra.

\section{CATEGORIZACIÓN DE PERSONAJES EN EL DISCURSO PUBLICITARIO ANALIZADO.}

\section{Bellos libertos.}

\section{a) Mujer objeto}

No es en sí un perfil propiamente juvenil, ni un perfil autóctono de un sector particular, aunque cuenta con gran presencia en los sectores automoción, moda y belleza. Es un recurso artístico propio de la función poética del mensaje publicitario, no se fundamenta en ningún estilo de vida, ni escenario, ni elemento cultural determinado por la antropología y la sociología de la juventud. Se manifiestan como mujeres objeto portadoras de los significados de belleza y erotismo, connotados por la seducción, la sensualidad o la inocencia o incluso expuestos de manera más explícita, recreando a la diosa afrodita. Como tal, no es un personaje utilizado para recrear la cultura juvenil, sino que cumple dos funciones fundamentales: a) portavoz del mensaje cuyas cualidades biológicas contribuyen a generar expectación y b) reflejo de la promesa de aquellos productos que ofertan el antienvejecimiento.

\section{b) Hombres objeto.}

Su presencia es frecuente en los sectores textil y belleza. Su función principal, como en el caso de las mujeres-objeto, es actuar como portavoces de la promesa del anuncio y expresar la belleza como cualidad natural de la juventud. Esta belleza se asocia con la virilidad y la seducción; no son, salvo casos aislados, meros objetos inanimados de deseo sexual, sino que poseen la cualidad de la seducción. Mientras que en la exposición de la mujer, ésta suele exhibirse de forma individual, los hombres suelen estar representados en compañía de una mujer seducida por los encantos de la 
virilidad y la vitalidad masculinas. Al igual que ocurre con la representación femenina, su edad se determina dentro del grupo de jóvenes adultos o mayores de 30 años.

Libertos tecnoculturales: Los denominamos así (siguiendo la terminología de Ruiz de Olabuenaga, 1998) por su cualidad de libertos o jóvenes cuya identidad viene determinada por la posesión de automóvil o teléfono móvil, la posesión de la cultura promovida por el objeto, o "sobjetos" como determina Vicente Verdú, "seres animados que reciben vida a través de la acción entre ellos y con los sujetos, dentro de la corriente que circula en su sistema y fuera de él, desde el deseo hasta la compra, desde la exhibición hasta la posesión” (2005:108). Jóvenes que utilizan los instrumentos tecnológicos de la cultura hegemónica de la que participan y los convierten en elementos de posesión de su propia cultura juvenil. Instrumentalizan los objetos hacia sus actividades focales, hacia el desarrollo de su propia identidad normalmente readicionada con el tiempo de ocio. La posesión y exhibición de aquellos les permite recrear su imagen extrovertida, divertida, marchosa y ser reconocidos por el grupo de iguales, de amigos; como tal, les proporciona en último sentido el reconocimiento social que ya no da el trabajo o la formación tradicional. Determina su estatus y es más importante que cualquier elemento cultural tradicional como la estética, la música o el lenguaje. No se asocia con ninguna corriente ideológica de las subculturas, ni promueve más acciones que la convivencia con sus iguales. Son instrumentos que permiten el tiempo de ocio y otorgan la identidad de los personajes; el móvil permite ver televisión, descargar música, navegar y chatear por Internet, pero estas actividades, al contrario de lo que ocurre con las tribus urbanas, no definen al individuo, sino que es la interacción con el objeto la que lo determina.

Modelos, tribus urbanas y currantes bohemios: Están presentes únicamente en el sector textil y, según nuestras estadísticas, su presencia no es la que cuenta con mayor frecuencia dentro de este sector. Poseen la función de representar al público objetivo y ser portavoces del mensaje a la vez. Sin embargo la representación de estilos de vida asociados a estilos de moda es cada vez más difícil por la amplia variedad de las mal llamadas actuales tribus urbanas, que no responden sino a tendencias estéticas, mediáticas y musicales demasiados efímeras para constituir una cultura en sí o como afirma Martin Dawber, "el número de tribus existentes actualmente en las ciudades es equivalente al número de marcas que han estado promoviendo prendas imprescindiblemente, algunas de las cuales llevarán asociadas para siempre una etiqueta 
y sobrevivirán incluso a la moda que las vio nacer" (2005:57). Cada vez más se impone el urban style o free style, estilo libre de vestir inspirado en las tendencias urbanas que ha dado la vuelta al reconocimiento de estilos y tribus urbanas clásicas, se han vuelto más sutiles, más difíciles de reconocer, "las prendas envuelven a quienes las visten en un manto de invisibilidad y les garantizan además que su vestimenta les identifica como parte de un grupo" (Dawber, 2005:57). El estilo de vestir clásico se ha transformado en neoclasicismo, un estilo clásico pero informal más ligero que asocia un aire de libertad a quien lo exhibe. Ante tal avalancha de estilos de moda, libres, sin ataduras marquistas que recreen estilos vida distintos, el sector textil apenas si ofrece una mínima muestra de la publicidad que las marcas recrean en revistas especializadas del sector dirigidas a un público juvenil. En el análisis realizado, cada marca plantea sus propias líneas de ropa sabiendo que las tendencias ya no están en las pasarelas sino en las calles, a la espera de que un coolhunter las potencie, de modo que prevalece la comunicación del producto, de la marca como tendencia inspirada en los estilos de cada temporada. Así, las marcas que promueven los jeans adaptan estos a las tendencias sociales del momento, como la campaña Organization de Lois, revitalizan los movimientos antiglobalización o como la marca Diesel, cuyo concepto de comunicación se argumenta en el espíritu de rebeldía con el que los consumidores juveniles se sientan identificados. Pero estos casos son aislados y exclusivos de este sector, no están presentes en el resto de sectores analizados y por tanto no podemos decir que la moda y las tendencias sociales que reflejan determinen la construcción de la categoría social de juventud en los anuncios gráficos del medio prensa. Sigue siendo un recurso expresivo al servicio de las marcas, sean o no del sector textil; ofrece un contexto actualizado del mensaje producido pero no un recurso fundamental por el que podamos establecer una clasificación de jóvenes personajes juveniles publicitarios. Así, en los anuncios gráficos del medio prensa, ni existe un reflejo fiel y constante de los estilos de vida juveniles, ni de las tendencias efímeras de moda urbanas ni la moda determina la creación de estos en ningún sector. Una cosa es la función semótica de la ropa o moda y otra el reflejo que la publicidad hace de las tendencias sociales, estéticas y textiles. La primera ayuda a posicionar al público objetivo, el estilo de vida o al producto anunciado; por ejemplo la relación existente entre la forma un sostén y el estatus de su personaje. La segunda determina en casos muy concretos la adaptación de las líneas de comunicación de 
algunas marcas, como el caso de Lois o Diesel, a los cambios sociales que nos afectan en nuestra vida cotidiana.

Marchosos desinhibidos y vitalistas: Constituyen el grupo de personajes jóvenes que configuran su identidad durante el tiempo de ocio, normalmente nocturno. Una identidad desinhibida de todo tipo de responsabilidad y construida a partir de la autenticidad, la amistad, la sensualidad y la diversión. Representan o son el paradigma de la sociedad posmoderna, definidos a partir de la carencia de grandes ideologías que determinan su personalidad. Su presencia está reducida, de manera casi exclusiva, a los sectores tabaco y bebidas alcohólicas. Sus actividades focales están siempre relacionadas con el tiempo de ocio, como salir con los amigos, ligar o viajar. Aunque sus escenarios más habituales son los bares o pubs, éstos son sustituidos cada vez más por la playa, la nieve, los jardines o el hogar como espacios del desarrollo individual y colectivo. En el primero de los casos, el desarrollo individual, propio del sector bebidas alcohólicas, se produce a partir de la recreación de individuos fantásticos, oníricos o mitológicos que actúan como portavoces del mensaje y que proporciona el valor a la marca a través de su imagen de autenticidad. Una autenticidad común a todas las marcas, independientemente de los significados que las diferencian entre sí.

Salvo en casos aislados, ningún anuncio de bebidas alcohólica o de tabaco toma como referencia la imagen de las tribus urbanas para construir los personajes que doten de significados a su marca. Si lo hacen, como en el caso de la marca de tabaco Benson Red, la representación es colectiva (yo motero, yo punk, yo cyber, etc.), global, que fomenta una identificación con la marca y no una ideología particular. Esto es así por la capacidad que tiene la imagen colectiva de las tribus urbanas de dotar de identidad a los individuos a partir de su imagen o moda de vestir, de la música y de la diversión.

Jóvenes deportistas de elite: Son habituales en los sectores automoción, telecomunicaciones y tabaco. Se corresponden con jóvenes deportistas cuyo éxito profesional suponen un importante reconocimiento social allí donde su anuncio es difundido. No son personajes inventados sino deportistas reales cuya actividad no se utiliza para reproducir una actividad focal juvenil sino por su naturaleza mediática y masiva. Cumplen distintas funciones según sea el sector en el que participan. Cuando están presentes en el sector automoción lo hacen para reforzar la cualidad física del producto anunciado, mientras que cuando lo hacen en los sectores telecomunicaciones y tabaco lo hacen como imagen de marca de productos o servicios dirigidos a un público 
eminentemente juvenil. Son portavoces del mensaje y transmisores de significados como el riesgo, la aventura, la diversión y el ocio tecnocultural (servicios de descargas de juegos para el móvil a través de MoviStar y Vodafone). Una última variedad de este tipo de personajes, la encontramos en el sector bebidas alcohólicas. En este caso, el deportista no es portavoz del éxito profesional, sino que desarrollan actividades focales de ocio, una vez más asociadas a la autenticidad; deportes cuya capacidad mediática está reducida a canales temáticos deportivos y sus tiempos de retransmisión son infinitamente inferiores a los anteriores (tenis, automovilismo y motociclismo). Bajo estrategias comerciales de patrocinio deportivo, marcas como J\&B y Ballantine's, desarrollan anuncios en los que la juventud está representada a partir de la plenitud vital de sus personajes masculinos y la belleza, en los femeninos; deportes como el voley playa o el snowboard reproducen escenarios deportivos originales y asociados al tiempo y los epacios de ocio y diversión (las playas en verano y las estaciones de esquí en invierno).

Jóvenes en transición a la vida adulta: Su representación cuenta con menor frecuencia que la de los anteriores en la muestra analizada, sin embargo, la constancia del significado asociado a su imagen los hace fácilmente identificables. Es una representación que deriva directamente de uno de los discursos producidos desde la cultura hegemónica para definir la juventud como etapa de transición a la vida adulta. Si hasta ahora los perfiles definidos se caracterizaban por una camaleónica representación, tanto en su imagen como en los significados que se les asocian, este tipo de jóvenes mantienen unas constantes que les identifican siempre más allá de la marca o anuncio que usa su imagen para construir su mensaje. En los personajes definidos antes hemos visto como los jóvenes no mantienen una constante, en cuanto a su uso, que otorgue un significado común para cada sector en el que participan, en el sector educación no ocurre lo mismo. El hecho de utilizar estos personajes a partir de un discurso particular y hegemónico que define a la juventud como una etapa transitoria de la vida, hace que en sí la juventud sí actúe, en este sector, como un concepto, como una imagen que en sí posee la cualidad de definir al personaje al margen del valor de la marca. Colectiva o individualmente se muestran imágenes de jóvenes en ámbitos educativos, sobre todo universidades, que fomentan la superación individual. Son antagonistas de los currantes bohemios puesto que otorgan a la formación educativa superior sus esperanzas de obtener un buen trabajo a partir del cual abandonen la etapa de transición, en la que 
están inmersos, y desarrollen su propia identidad a través del éxito profesional, que a su vez les permitirá realizar su proyecto vital. Como tal es el perfil juvenil menos posmoderno puesto que como hemos visto se construye a partir de la existencia de instituciones hegemónicas que participan del proceso de cultural juvenil reproduciendo los grandes discursos modernos que explican lo que es y debe ser la juventud, una transición vital hacia el verdadero desarrollo identitario.

\section{CONCLUISIONES}

Como hemos reflejado en los epígrafes anteriores es complejo establecer un decálogo de personajes juveniles claramente definidos en el discurso publicitario. Esta complejidad resulta, en primer lugar, de la construcción intencionada de los mismos que están siempre al servicio de los propósitos comerciales del anunciante. Las imágenes juveniles acompañan el lanzamiento de un nuevo producto, resaltan las cualidades de un nuevo servicio, actúan como recurso creativo, forman parte de la figura retórica que ayuda a crear el sentido del mensaje, constituyen o albergan los valores intangibles de una marca, como la sensualidad o la libertad, pero también, en su conjunto, en la suma de imágenes que conforman el discurso visual, configuran una cultura visual publicitaria propiamente juvenil. Esto provoca que las imágenes juveniles en los anuncios no construyan o muestren una cultura juvenil centrada en los escenarios o elementos culturales tradicionales establecidos desde la Sociología y la Antropología, donde la música, la estética, el lenguaje o las acciones focales determinaban la imagen de los jóvenes y de sus subculturas. Cuando un anuncio alberga la imagen de uno o varios jóvenes, éstos no actúan, siempre, como las promesas del anunciante o como los conceptos de comunicación creativa; la juventud no es ni siempre se utiliza como un concepto comunicativo como tal. Por la condición sociocultural del contexto en el que se difunden estos anuncios, la imagen de la juventud se ha asociado tradicionalmente, en publicidad, a los significados físicos como la belleza femenina, el estado biológico de plenitud vital masculina o simplemente se ha usado como recurso artístico-estético. Sin embargo, la evolución creativa publicitaria llevada a cabo todo el mundo y, en el caso que nos ocupa, en España, en los últimos 40 años, ha dado paso a la aplicación de modelos de producción de mensajes publicitarios alejados, cada vez más, de las cualidades o propiedades del producto para convertirse en ventanas de sentidos por las 
que aprender tendencias sociales de toda índole e que incluso provocan la aparición de tendencias en los ámbitos de la vida cotidiana. Aplicado a nuestro estudio esto deviene en una imagen de la juventud que evoluciona según las necesidades económico-sociales de los mercados (internacionales) y de las marcas que los hacen existir.

La juventud, pues, está presente en el discurso publicitario como categoría sociocultural reconocida por todos sin que el mensaje tenga que recordarnos que así es a partir de cada uno de los léxicos que la componen. Para el medio prensa, que es el que aquí analizamos, los mensajes se aprovechan de la conexión indivisible de las tres dimensiones del lenguaje, sintaxis, semántica y pragmática, que permiten al receptor componer su propio mensaje final, en función de una suma de factores incontrolables para el anunciante. La conexión entre mensajes publicitarios de una misma marca diseñados para distintos medios, la adaptación a los mismos, los mensajes de la competencia, el grado de atención e interés y otros muchos factores individuales de cada lector, conllevan, no sólo que cada anunciante recree escenarios y actores cuyo sentido y eficacia permanezcan inalterables en el tiempo, sino que estos sentidos evolucionarán silenciosamente, albergados en el sistema de la marca y garantizando la existencia de ésta. Este trabajo constante de las marcas permite que la publicidad pueda crear textos, anuncios, cuya interpretación sea inherente al texto, al anuncio, favoreciendo la interpretación del lector y reduciendo los riesgos del contexto externo en el que se difunde.

En este marco, la publicidad tiene la capacidad de generar mensajes cuyos significados superan la semántica de los signos y el contexto en el que se distribuyen; son capaces de simular, de recrear, de ir más allá generando el suyo propio, en el que los jóvenes ya no son un estado biológico más, son el único; dejan de ser entendidos a partir de los discurso sociales que les han explicado y participan de una realidad, si quiere llamarse, mitológica. De este modo, el discurso producido parte de un contexto propio que los define, el sector del que participa la marca o anunciante, y cuenta con sus propios individuos cuyos roles participan en la construcción del mensaje anunciando el producto, transfiriendo o asumiendo sus cualidades, recreando realidades fantásticas o reproduciendo fielmente su igual en el mundo real. Así la construcción de personajes juveniles en el discurso publicitario no viene determinada de antemano por un conjunto de variables que los definan. Sí se utiliza para su construcción elementos de su propia cultura, pero para crear la suya propia, la del contexto del anuncio, no parece que 
vengan definidos por estéticas determinadas de una moda particular o un estilo musical como ocurría con las tribus urbanas y el discurso antropológico de las subculturas.

Aceptamos así, la narratividad de los textos propuesta por Paolo Fabri (2001) para determinar nuestra categorización de personajes juveniles a partir de la capacidad de la publicidad por generar su propio sentido interno derivado de su propio contexto (el sector al que pertenece), de su propia individualidad (la marca que nomina), del sentido de la marca (los valores que la definen), de la materialización física en forma de producto o servicio ofertado, de la promesa que diferencia a éstos y de la expresión o concepto utilizado para su comunicación. En este contexto, donde la marca determina el mensaje del anuncio, la construcción de los personajes juveniles no deriva de los elementos culturales que el contexto sociocultural o la cultura hegemónica identifica como propios. La publicidad utilizará estos elementos, ya sean estéticos, musicales o gramaticales, y sus escenarios cuando lo considere oportuno, pero no como una norma indispensable para generar el sentido final del mensaje deseado. Estará condicionado a las características de sus receptores, sean o no consumidores, a sus gustos, a sus preferencias, pero el sentido final estará siempre en el propio texto. La conexión de estos textos (a través de su presencia de distintos medios, las adaptaciones de los mensajes, las oposiciones de la competencia, etc.) producirá un discurso general y más abstracto, pero no todos los textos permiten esta conexión. En este sentido ni el ocio, ni la tecnocultura, ni la moda se mantienen constantes en todos los textos de manera que determinen un discurso en el que la juventud representada se defina por los significados asociados a dichos conceptos. El ocio está presente como actividad focal de muchos personajes en diferentes contextos, pero no es una cualidad de todos los personajes, al igual que no lo es la cultura digital, ni la moda, ni elementos culturales tradicionales como la música, las estéticas de las diferentes subculturas, ni el lenguaje convertido en jerga juvenil. La diversidad de textos promueve discursos publicitarios, universos de marca, no un discurso. Sin embargo, apreciamos que existen elementos de expresión y sentido común, en el que podemos apreciar repetición de personajes, a partir de sus cualidades físicas o expresivas, adaptadas al contexto promovido desde dichos discursos. El sentido del texto publicitario nace y muere en el texto; algunos personajes nacen y mueren en el texto, otros lo hacen en el contexto y otros participan de todos los contextos. 
Podemos, finalmente, hablar de elementos de la cultura juvenil promovidos en contextos publicitarios, no de una cultura juvenil común promovida en un discurso publicitario unitário (global). Podemos identificar a un rapero, averiguar su origen antropológico, determinar sus actividades y elementos culturales que les definen y ubicarlo en un anuncio; en definitiva podemos recrear la imagen de un rapero en el contexto sociocultural y podemos construir el mensaje a partir de su imagen arquetipo o estereotipada del rapero o de un deportista de elite. Podemos distinguir representaciones juveniles exhibidas en personajes con características similares pertenecientes a contextos publicitarios distintos entre sí, pero no un catálogo de personajes juveniles definidos a partir de elementos claramente identificables que siempre podamos encajar en cualquier texto de manera que guarden, al mismo tiempo, su sentido, su identidad, a partir de la imagen recreada. De este modo, podemos afirmar que el concepto social de juventud alberga distintos significados que actúan para promover la promesa del producto.

\section{REFERÊNCIAS BIBLIOGRÁFICAS}

CARO, A "Fundamentos epistemológicos y metodológicos para el estudio científico de la publicidad" en Pensar la Publicicdad. Revista internacional de investigaciones publicitarias, $\mathrm{n}^{\mathrm{o}}$ 1, vol 1, Madrid, 2007, p 55-82.

COMAS, D. Jóvenes y estilos de vida. Valores y riesgos en los jóvenes urbanos. Madrid, Injuve, 2003.

DAWBER, M. Marcar tendencias. Ilustradores de moda contemporâneos. Barcelona, Gustavo Gili, 2005

EGUIZABA, R. Industrias de la conciencia. Una historia de la publicidad en España (1975-2009). Barcelona, Península, 2009.

FABRI, P. La táctica de los signos. Barcelona, Gedisa, 2001.

FEIXA, C. De jóvenes, bandas y tribus. Barcelona, Ariel, 1998.

GONZÁLEZ MARTÍN, J.A. Teoría general de la publicidad. Madrid, Fondo de cultura económica, 1996.

Hebdige, D. Subcultura. El significado del estilo. Paidós, Barcelona, 2004.

LEÓN, J. L. Mitoánalisis de la publicidad. Barcelona, Ariel, 2001.

LIPOVETSKY, G. La felicidad paradójica. Barcelona, Anagrama, 2007. 
Análisis crítico de la imagen de la juventud en el discurso publicitario

de Miguel Angel Nicolas Ojeda

MARTÍN CRIADO, E. Producir la juventud. Madrid, Istmo, 1998.

MARTÍN SERRANO, M "Visión del mundo y uso de la información en los jóvenes", en Revista de estudios de Juventud, n³3, Madrid, 1989,15-22.

MONTESINOS, D. La juventud domesticada. Como la cultura juvenil se convirtió en simulacro. Madrid, Edición Popular, 2007.

NICOLÁS OJEDA, M.A. Publicidad y Juventud. Aspectos teóricos sobre el concepto social de juventud y su estudio desde la disciplina publicitária. Madrid, Vision Libros, 2008.

REVILLA, JC. La identidad personal de los jóvenes: pluralidad y autenticidad. Madrid, Entinema, 1998.

RODRIGO ALSINA, M. Los modelos de la comunicación. Madrid, Tecnos, 1995.

RUIZ DE OLABUENAGA. La juventud liberta. Género y estilos de vida de la juventud urbana española. Madrid, Fundación BBV, 1998.

Artigo recibido: 27/7/10

Artigo aprobado: 10/9/10 